\title{
The Impact Of Online Quizzing On Student Success In An Introductory Financial Accounting Class
}

G. R. Cluskey Jr., (Email: bcluskey@westga.edu), University of West Georgia Charles W. Hodges, (Email: chodges@westga.edu), University of West Georgia Sondra Smith, (Email: sondras@westga.edu), University of West Georgia

\begin{abstract}
We document the impact of transitioning to online quizzing in an introductory Financial Accounting course. Results show significantly increased course pass rates, significantly increased individual exam averages, and lower overall drop rates.
\end{abstract}

\section{INTRODUCTION}

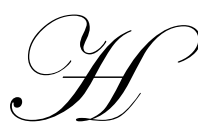

ybrid course delivery combines conventional face-to-face instruction with distance education in the same course. There is extensive literature on university student attitudes and performance as courses transition from traditional discussion/lecture courses to hybrid courses to pure distance learning courses. This paper documents the transition from a Fall 2004 traditional face-to-face introductory Financial Accounting course to a Spring 2005 hybrid Financial Accounting course. After controlling for the instructor, exams, and number of students, we found significantly improved student performance and course pass rates.

Our primary reason for changing from a traditional course to a hybrid course was to ensure students were studying course material on a continuous, ongoing basis. This was accomplished via the implementation of graded WebCT-based quizzes for each chapter covered. By adding these online quizzes, students weren't able to procrastinate and study several chapters (i.e. cram) the night before the test. Since accounting is a subject that requires an individual to ingest information in small proportions, the online quizzes enable the students to study and master one chapter before attempting the next. Many students do not have a basic knowledge of how to prepare for and take a multiple choice test. These online quizzes (which are predominantly multiple choice questions) help prepare students for the actual exams. Perhaps the most important reason for this change was to improve students' grades and decrease drop rates.

A hybrid environment can be compared to a buffet. By giving the traditional lectures, supplemental materials online, assignments, online quizzes, and office hours by the professor, students have a wide array of learning tools to choose from. It satisfies all three learning styles: visual, auditory and kinesthetic.

\section{LITERATURE REVIEW:}

The transition from traditional face-to-face courses to hybrid courses in university academic disciplines has been examined in many settings. Most studies find similar levels of student performance between traditional courses and hybrid courses. However, student satisfaction tends to decrease as the distance-learning components of a course increases. Carr (2000) finds undergraduates enrolled in an introductory psychology course performing better in distance education courses, but were generally less happy with them. Students in the web-based course consistently scored an average of five percentage points higher on the final exam than did those in the lecture course, but they consistently reported less satisfaction than students in the lecture course. Carr surmised that one of the reasons for less 
satisfaction could be more time required to complete assignments. Rivera and Rice (2002) compare traditional lecture/discussion format with a hybrid and pure distance education in introductory Information Systems courses.

Their results indicated similar levels of student performance and lowered satisfaction levels as the distance learning components increased. Johnson (2005) documents the overall improved performance by hybrid courses with introductory psychology courses, but her findings suggest that peer alienation was associated with increased WebCT use; learning alienation and course alienation were associated with low WebCT use. Learning alienation demonstrated an inverse relation to academic achievement. In most cases, significant predictive relationships between academic achievement and student use of WebCT were curvilinear.

Examinations of hybrid models in introductory accounting courses finds results similar to other academic disciplines, with one key difference. Rather than similar levels of performance, the level of student performance shows a curvilinear relationship as the level of distance learning increases. Specifically, traditional and pure distance learning courses have similar levels of student performance while hybrid courses have increased levels of student performance. Dowling, Godfrey, and Gyles (2003) investigated the association between the learning outcomes of students and two teaching models: a traditional face-to-face lecture/tutorial teaching model and a hybrid flexible delivery model in an introductory accounting course. They found that academic performance is higher for students who studied under the flexible delivery model, achieved higher marks in prerequisite units, were female, or were younger. Their results suggest that flexible delivery teaching models utilizing electronic delivery media can be used to achieve the benefits of small class sizes when teaching large student numbers. Frank (2000) finds no difference in performance for traditional versus pure distance learning introductory financial accounting courses. De Lange, Suwardy and Mavondo (2003) examine performance and attitude of introductory accounting as related to the number of design features and attributes of WebCT (e.g. bulletin boards, on-line assessment and chat room). Their study found that increased student satisfaction is significantly associated with the provision of: lecture notes, bulletin board, on-line assessment and other tools (chat and video summaries).

\section{Methodology}

In Fall 2004 (http://www.westga.edu/ accfin/A2101SmithF04.pdf), the University of West Georgia taught a traditional lecture based introductory Financial Accounting course using the fourth Edition of Edmonds, et al., Fundamental Financial Accounting Concepts (2003). In Spring 2005 (http://www.westga.edu/ accfin/A2101Smith Sp05.pdf), a hybrid course model combining traditional lecture with web based supplemental material and WEBCT quizzes was created. The web-based supplemental material was the unmodified WEBCT material provided by the textbook publishers.

There were three significant differences between the two courses. The first was the different weighting used in the assignment of grades (See Table 1). The second was an increase in supplemental material available to students. The third was implementation of required, and graded, WEBCT quizzes.

\begin{tabular}{|l|c|}
\hline \multicolumn{2}{|c|}{ Table 1: Comparison of Grading Schemes } \\
\hline Fall 2004 Introductory Financial Accounting & $25 \%$ \\
\hline Classroom Exam 1 & $25 \%$ \\
\hline Classroom Exam 2 & $25 \%$ \\
\hline Classroom Exam 3 & $25 \%$ \\
\hline Final Exam & $100 \%$ \\
\hline Maximum & \\
\hline Spring 2005 Introductory Financial Accounting & $20 \%$ \\
\hline Classroom Exam 1 & $20 \%$ \\
\hline Classroom Exam 2 & $20 \%$ \\
\hline Classroom Exam 3 & $20 \%$ \\
\hline WebCT Quiz average & $20 \%$ \\
\hline Final Exam & $100 \%$ \\
\hline Maximum & \\
\hline
\end{tabular}




\begin{tabular}{|c|c|c|c|c|}
\hline \multicolumn{5}{|c|}{ Table 2: Demographic Data and Final Grades by Semester } \\
\hline & Fall 2004 & $\%$ of total & Spring 2005 & $\%$ of total \\
\hline \# students before drops & 247 & & 260 & \\
\hline \# sections & 3 & & 3 & \\
\hline '01 & 90 & $36.44 \%$ & 89 & $34.23 \%$ \\
\hline '02 & 87 & $35.22 \%$ & 90 & $34.62 \%$ \\
\hline '03 & 70 & $28.34 \%$ & 81 & $31.15 \%$ \\
\hline \multicolumn{5}{|l|}{ Sex } \\
\hline Female & 124 & $50.20 \%$ & 132 & $50.77 \%$ \\
\hline Male & 123 & $49.80 \%$ & 128 & $49.23 \%$ \\
\hline \multicolumn{5}{|l|}{ \# of Repeats } \\
\hline $2^{\text {nd }}$ time & 8 & $3.24 \%$ & 7 & $2.69 \%$ \\
\hline $3^{\text {rd }}$ time & 3 & $1.21 \%$ & 3 & $1.15 \%$ \\
\hline 4th time & 2 & $0.81 \%$ & 1 & $0.38 \%$ \\
\hline 5th time & 0 & $0.00 \%$ & 2 & $0.77 \%$ \\
\hline \multicolumn{5}{|l|}{ Class } \\
\hline Freshman & 63 & $25.51 \%$ & 40 & $15.38 \%$ \\
\hline Sophomore & 138 & $55.87 \%$ & 153 & $58.85 \%$ \\
\hline Junior & 30 & $12.15 \%$ & 55 & $21.15 \%$ \\
\hline Senior & 15 & $6.07 \%$ & 9 & $3.46 \%$ \\
\hline Graduate & 1 & $0.40 \%$ & 3 & $1.15 \%$ \\
\hline \multicolumn{5}{|l|}{ Age } \\
\hline $18-20$ & 125 & $50.61 \%$ & 81 & $31.15 \%$ \\
\hline $21-22$ & 78 & $31.58 \%$ & 130 & $50.00 \%$ \\
\hline $23-30$ & 30 & $12.15 \%$ & 37 & $14.23 \%$ \\
\hline $31-40$ & 8 & $3.24 \%$ & 12 & $4.62 \%$ \\
\hline over 40 & 6 & $2.43 \%$ & 0 & $0.00 \%$ \\
\hline \multicolumn{5}{|l|}{ Withdrawals } \\
\hline Total withdrawals & 103 & $41.70 \%$ & 87 & $33.46 \%$ \\
\hline Hardship w/d & 1 & $0.97 \%$ & 1 & $1.15 \%$ \\
\hline Drop b/f 1st test & 6 & $5.83 \%$ & 4 & $4.60 \%$ \\
\hline Drop b/f 2nd test & 31 & $30.10 \%$ & 24 & $27.59 \%$ \\
\hline Drop after 2nd test & 64 & $62.14 \%$ & 57 & $65.52 \%$ \\
\hline Drop after midpoint & 1 & $0.97 \%$ & 1 & $1.15 \%$ \\
\hline \multicolumn{5}{|l|}{ Cumulative GPA } \\
\hline $3.50-4.00$ & 19 & $7.69 \%$ & 17 & $6.54 \%$ \\
\hline $3.00-3.49$ & 60 & $24.29 \%$ & 49 & $18.85 \%$ \\
\hline $2.50-2.99$ & 66 & $26.72 \%$ & 88 & $33.85 \%$ \\
\hline $2.00-2.49$ & 84 & $34.01 \%$ & 87 & $33.46 \%$ \\
\hline Less than 2.00 & 18 & $7.29 \%$ & 19 & $7.31 \%$ \\
\hline \multicolumn{5}{|l|}{ Final Grade } \\
\hline A's & 22 & $8.91 \%$ & 28 & $10.77 \%$ \\
\hline B's & 39 & $15.79 \%$ & 37 & $14.23 \%$ \\
\hline C's & 33 & $13.36 \%$ & 51 & $19.62 \%$ \\
\hline D's & 37 & $14.98 \%$ & 40 & $15.38 \%$ \\
\hline F's & 13 & $5.26 \%$ & 16 & $6.15 \%$ \\
\hline W's & 102 & $41.30 \%$ & 86 & $33.08 \%$ \\
\hline WF's & 1 & $0.40 \%$ & 1 & $0.38 \%$ \\
\hline Never attended & 0 & $0.00 \%$ & 1 & $0.38 \%$ \\
\hline
\end{tabular}

The quizzes were chapter quizzes with 20 questions/problems per quiz. These questions/problems were drawn randomly from the textbook test bank and textbook's chapter-based WEBCT quizzes. Students were allowed 
three attempts per quiz with the highest grade counting towards their quiz average. There were twelve quizzes consisting of eleven chapter quizzes plus one end-of-course quiz covering ethics and international business. The ethics and international business quiz is part of our AACSB Assurance of Learning program. The two lowest quiz grades were dropped, and the top ten quiz grades were averaged which equated to one test grade. The level of difficulty on questions/problems on the Spring 2005 WEBCT quizzes was generally greater than the difficulty of exams.

Several aspects of the course were unchanged. The same instructor was responsible for all sections in both terms. Students were still required to complete un-graded assignments, consisting of exercises and problems from each chapter. In both Fall 2004 and Spring 2005, the exams given to the students were identical. As shown in Table 2, the quality, quantity, and demographics of the students was similar in both semesters. There was a slight difference in the level of students with the Fall semester having about 10\% more freshmen and $10 \%$ fewer juniors than the Spring semester. Corresponding to the class difference, the Fall semester had slightly younger students with slightly higher Grade Point Averages.

\section{RESULTS}

To facilitate comparison of the two teaching methods, identical exams were administered in the Fall and Spring semesters. Table 3 compares the results for the four identical exams. Our discussion of results focuses on Exam 1, Exam 2, and the overall course completion rate. Due to instructor illness, different instructors were responsible for teaching and administering Exam 3 and Exam 4. Our null hypothesis was that performance would be unaffected by the transitions from a traditional course to a hybrid course. Our alternate hypothesis was that student performance would improve with the transition to a hybrid course.

From Table 3 it is clear that Exam 1 and Exam 2 scores increased significantly between Fall 2004 and Spring 2005. Similarly it is clear that Spring 2005 exam scores were lower for Exam 3 and Exam 4, when compared to Fall 2004. While slightly fewer students attempted Exam 1 in Spring 2005 (92.69\% versus 94.33\%), this pattern reversed for Exams 2 (78.08\% versus 74.09\%), and Exam 3 (63.85\% versus 58.30\%). For Exam 4 the higher attempt rate (62.31\% versus 56.28\%) was significant at the $10 \%$ level. The higher attempt rate on Exam 4 was consistent with the significantly higher course pass rate $(60.2 \%$ versus $53.0 \%)$ for the Spring semester. While the percent of students successfully completing the course was higher, the course grade point average was slightly lower (2.04 versus 2.12).

The lower scores on Exams 3 and 4 could be due to many factors. One clear issue was the adhoc nature of instruction over the last third of the course. While all of the replacement instructors were experienced in teaching the introductory financial accounting course, none were familiar with WebCT or teaching a hybrid course. Some instructors were not aware of the weekly chapter quizzes and none initially had instructor login permission needed to make changes to the WebCT site. An untested instructor perception was that many students were content to pass the course with a C or D. After the second exam, many students found themselves with B or above averages. This high average for the first two exams combined with the $20 \%$ of the grade from chapter quizzes meant that students could make D or high $\mathrm{F}$ on the last two exams and would still have an overall passing grade. 


\begin{tabular}{|c|c|c|c|c|c|}
\hline \multicolumn{6}{|c|}{ Table 3: Exam Results By Semester } \\
\hline & Fall 2004 & $\begin{array}{l}\text { \% Attempting } \\
\text { Exam }\end{array}$ & Spring 2005 & $\begin{array}{c}\text { \% Attempting } \\
\text { Exam }\end{array}$ & T-Statistic \\
\hline \multicolumn{6}{|l|}{ Test 1} \\
\hline \# students & 233 & $94.33 \%$ & 241 & $92.69 \%$ & -.61 \\
\hline average $b / f$ curve & 64.43 & & 72.33 & & $4.89 * * *$ \\
\hline Curve & 3 & & 0 & & \\
\hline \multicolumn{6}{|l|}{ Test 2} \\
\hline \# students & 183 & $74.09 \%$ & 203 & $78.08 \%$ & 1.05 \\
\hline average $b / f$ curve & 61.95 & & 67.46 & & $3.00 * * *$ \\
\hline curve & 7 & & 7 & & \\
\hline \multicolumn{6}{|l|}{ test 3} \\
\hline \# students & 144 & $58.30 \%$ & 166 & $63.85 \%$ & 1.27 \\
\hline average $b / f$ curve & 72.63 & & 65.42 & & -3.80 \\
\hline curve & 3 & & 7 & & \\
\hline \multicolumn{6}{|l|}{ test 4} \\
\hline \# students & 139 & $56.28 \%$ & 162 & $62.31 \%$ & $1.38 *$ \\
\hline average $b / f$ curve & 59.54 & & 53.13 & & -3.21 \\
\hline curve & 10 & & 7 & & \\
\hline $\begin{array}{l}\text { Overall Grade Point } \\
\text { Average }\end{array}$ & 2.70 & & 2.66 & & -.84 \\
\hline $\begin{array}{l}\text { Course Grade Point } \\
\text { Average }\end{array}$ & 2.12 & & 2.04 & & -.58 \\
\hline $\begin{array}{l}\text { Students Passing Course } \\
\text { With D Or Above }\end{array}$ & $131(53.0 \%)$ & & $156(60.2 \%)$ & & $1.64 *$ \\
\hline
\end{tabular}

*** indicates significance at $1 \%$ with one-tailed t-test assuming unequal variances

$* *$ indicates significance at $5 \%$ with one-tailed t-test assuming unequal variances

* indicates significance at $10 \%$ for test for the difference between two sample proportions

\section{CONCLUSION}

As stated in the introduction, our primary reason for changing from a traditional course to a hybrid course was to ensure students were studying course material on a continuous, ongoing basis. This was accomplished via the integration of WebCT-based quizzes for each chapter covered. It is quite possible that replacing ungraded homework with graded homework would have had similar or possibly greater results. However, attempting to grade, each week, 60 problems for 270 students was not feasible. Additionally, the WEBCT quizzes give instant feedback, whereas graded homework would have delayed feedback.

We believe the transition from a traditional course to a hybrid course was beneficial in many ways. The transition was beneficial to students. Students, despite the higher workload, perceived the course as fairer with fewer exam surprises. Students felt they were better prepared for the exams and exam averages significantly improved. A second factor was familiarity with the course testing methodology. Due to the size of the classes, multiple-choice exams are the norm in our introductory accounting courses. As the quizzes were also (mostly) multiple choice, students were prepared for this style of exam questions. Third, online quizzing increased student participation both in and out of class. Classroom attendance was higher and students seemed more focused. Out of class, students were more likely to use the instructors' office hours between exams, rather than just before or after an exam.

The transition was also beneficial to Accounting instructors. Several instructors who had resisted distance learning technologies adopted the technology over the following two semesters. The adopting instructors appeared to be motivated by the increased student interest and the improved student outcomes. Instructors saw that course 
workload could be reduced by making supplemental material available and via WebCT's automatic grading of quizzes. Another factor was reduced student complaints. As the difficulty of the WEBCT quizzes exceeded the difficulty of the course exams, and because more students were passing the course, complaints to instructors were reduced.

Additional benefits (statistical tests not yet performed) have continued for the Summer 2005 and Fall 2005 semesters. The higher pass rates and higher student satisfaction in the introductory financial accounting course has continued with the Summer 2005 and Fall 2005 semesters. The second introductory accounting course, managerial accounting, switched to a hybrid model in the Fall 2005 semester. Because of increased student understanding of the material, there is a subjective belief that more students are considering accounting as a major. Finally, as students are doing better in the course with higher exam scores, lower drop rates, and higher pass rates, this improves retention in the college of business while simultaneously reducing the size of future introductory accounting classes.

\section{REFERENCES}

1. Carr, S., 2000, Online psychology instruction is effective, but not satisfying, study finds. Chronicle of Higher Education, 46(27), 2-5.

2. De Lange, P. T. Suwardy, and F Mavondo, 2003, Integrating a virtual learning environment into an introductory accounting course: determinants of student motivation. Accounting Education 12(1), 1-14.

3. Dowling, C., J. M. Godfrey, and N. Gyles, 2003, Do hybrid flexible delivery teaching methods improve accounting students' learning outcomes? Accounting Education 12(4), 373-391.

4. Frank, S. L., (2000), Collaborative Learning and web-based instruction in a cognitive apprenticeship model, Developments in Business Simulation \& Experiential Learning, 27, 188-194.

5. Johnson, G. M., 2005, Student Alienation, Academic Achievement, and WebCT Use. Educational Technology \& Society, 8(2), 179-189.

6. Rivera, J.C. and M.L. Rice, 2002, A comparison of student outcomes \& satisfaction between traditional \& web based course offerings. Online Journal of Distance Learning Administration, 5(3), 12 pages. 